\title{
ESPAÑA POR EL CAMBIO
}

Este pequeño artículo pretende solamente proporcionar al lector una primera y urgente entrega de los datos correspondientes a las elecciones geñerales celebradas en España el día 28 de octubre de 1982. El número 18 de la Revista de Derecbo Político incluirá análisis más detallados de los resultados de esta convocatoria electoral.

De los datos que ofrezco a continuación pueden extraerse múltiples conclusiones, y todas ellas serán expuestas y detalladas con posterioridad. Me limitaré de momento a resaltar los tres aspectos que -en mi opinión- confieren a estas elecciones legislativas el carácter de históricas.

En primer lugar (Cuadro 1), el electorado español acudió a la cita masivamente -incluso en las zonas geográficas tradicionalmente abstencionistas-, rompiendo la abstención y refrendando con su voto su apoyo a las instituciones. democráticas, a la Corona y a la Constitución y desautorizando pacíficamente a los que pretendieron desautorizar a la soberanía popular por medio de las armas.

En segundo lugar (Cuadro 2), el esquema de partidos políticos imperante en España desde el comienzo de la transición democrática ha quedado totalmente desfigurado. $\mathrm{Ha}$ sido éste un período electoral en el que, más que cualquier otro argumento, la dialéctica izquierda-derecha ha pesado definitivamente sobre el cuerpo electoral y ha dado como fruto este nuevo sistema, el bipolar, sin que de ello deba deducirse necesariamente que nos encontremos ante el mapa electoral futuro a largo plazo.

$\mathrm{Y}$ en tercer lugar, la victoria del PSOE ha sido arrolladora. Por primera vez desde la restauración de la democracia un partido político alcanza la mayoría absoluta en elecciones generales. Por vez primera también se formará en España un Gobierno de izquierdas desde la guerra civil, una guerra que ha quedado enterrada al fin por los votos de todos los españoles.

Fernando Ollero Butler 
Cuadro 1

LA ABSTENCION FRENADA

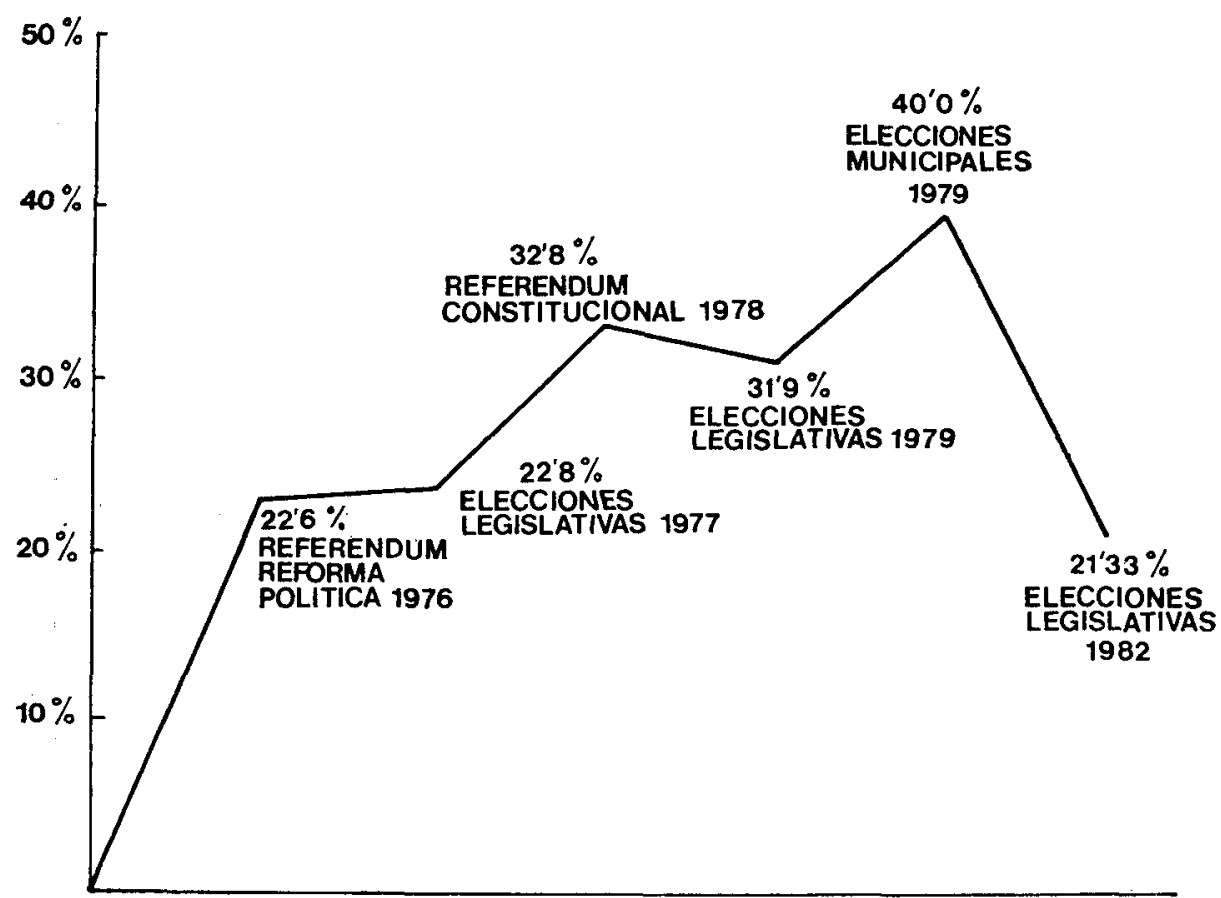


CUADro 2

DATOS COMPARATIVOS 1979-1982

\begin{tabular}{|c|c|c|c|c|c|c|c|c|c|c|}
\hline & Votos 1982 & $\%$ & Votos 1979 & $\%$ & $\begin{array}{c}\text { Escaños } \\
1982\end{array}$ & $\begin{array}{l}\text { Escaños } \\
1979\end{array}$ & $\begin{array}{l}\text { Variación } \\
\text { votos }\end{array}$ & $\begin{array}{l}\text { Variación } \\
\text { escaños }\end{array}$ & $\begin{array}{c}\text { Senado } \\
1982\end{array}$ & $\begin{array}{c}\text { Senado } \\
1979\end{array}$ \\
\hline PSOE & 9.836 .579 & 46,07 & 5.469 .813 & 30,50 & 201 & 121 & +4.36 & +80 & 134 & 70 \\
\hline $\mathrm{AP}-\mathrm{PDP}^{1} \quad \ldots \quad \ldots$ & 5.412 .401 & 25,35 & 1.067 .732 & 5,76 & 10 & & +4.344 & & 53 & 3 \\
\hline $\begin{array}{llllll}U C D & \ldots & \ldots & \ldots & \ldots\end{array}$ & 1.549 .447 & $\mathbf{7 , 2 6}$ & 6.268 .593 & 34,96 & 13 & 168 & -4.719 .146 & -155 & 4 & 119 \\
\hline 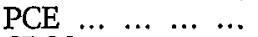 & 824.978 & $\mathbf{3 , 8 7}$ & 1.911 .217 & 10,81 & 5 & 23 & -1.086 .239 & -18 & - & 1 \\
\hline $\operatorname{CDS}^{2} \ldots \ldots \ldots$ & 615.540 & 2,89 & - & - & 2 & - & - & - & - & - \\
\hline$\ldots \ldots \ldots$ & 794.554 & $\mathbf{3 , 7 3}$ & 483.353 & 2,70 & 12 & 8 & +311 & +4 & 7 & 1 \\
\hline $\mathrm{PNV}^{4} \ldots \ldots \ldots$ & 406.804 & 1,91 & 275.292 & 1,54 & 8 & 7 & +131.512 & +1 & 7 & 8 \\
\hline $\begin{array}{llllll}\mathrm{HB}^{5} & \ldots & \ldots & \ldots & \ldots\end{array}$ & 206.748 & 0,97 & 172.1 & 0,96 & 2 & 3 & +34 & -1 & - & 1 \\
\hline $\begin{array}{llllll}\mathrm{EE}^{6} & \ldots & \ldots & \ldots & \ldots\end{array}$ & 98.652 & 0,47 & 85.677 & 0,48 & 1 & 1 & +12.975 & - & - & - \\
\hline $\operatorname{ERC}^{7} \ldots \ldots \ldots$ & 140.870 & 0,66 & 123.452 & 0,69 & 1 & 1 & +17.418 & - & - & - \\
\hline & \multicolumn{4}{|c|}{ Censo: 26.837 .212} & \multicolumn{3}{|c|}{ Votantes: 21.353 .996} & \multicolumn{3}{|c|}{ Abstención: $20,43 \%$} \\
\hline
\end{tabular}

1 Alianza Popular en coalición con el Partido Demócrata Popular. ${ }^{2}$ Centro Democrático y Social (A. Suárez). ${ }^{3}$ Convergènçia 1 Unió. 4 Partido Nacionalista Vasco. 5 Herri Batasuna. 6 Euskadiko Ezkerra. 7 Esquerra Republicana de Catalunya. 